\title{
CONEXIONES EN RED CON OTROS TIEMPOS, ESPACIOS Y GENERACIONES. ROGER SCRUTON, TRADICIONES Y EDUCACIÓN
}

\author{
Network connections with other times, places and \\ generations. Roger Scruton, traditions and education
}

María G. AMILBURU

Universidad Nacional de Educación a Distancia. España.

mgamilburu@edu.uned.es

bttps://orcid.org/0000-0002-2161-5181

Fecha de recepción:16/06/2020

Fecha de aceptación: 03/08/2020

Fecha de publicación en línea: 01/11/2020

Cómo citar este artículo: G. Amilburu, M. (2021). Conexiones en red con otros tiempos, espacios y generaciones. Roger Scruton, tradiciones y educación. Teoría de la Educación. Revista Interuniversitaria, 33(1), 35-49. https://doi.org/10.14201/teri.23463

RESUMEN

Hoy es frecuente menospreciar el valor de las tradiciones culturales, científicas o de pensamiento, porque remiten y nos vinculan a un tiempo que ya pasó. Y quienes defienden la función esencial que éstas desempeñan en la vida humana y en la tarea educativa, son tachados de conservadores y falsamente acusados de querer encerrarse en el pasado, como si fueran enemigos del progreso, el desarrollo y la innovación. En este artículo se analiza un modo diferente de entender la tradición, que sostienen reconocidos autores contemporáneos como R. Scruton, A. MacIntyre y R. S. Peters. Para ellos, asumir las tradiciones establece fecundas redes intencionales con quienes nos precedieron, con nuestros contemporáneos y con quienes aún no han nacido, favoreciendo así que la humanidad pueda seguir progresando. De acuerdo con la naturaleza teórica de este trabajo, se emplea una metodología propia de la Filosofía de 
MARÍA G. AMILBURU

CONEXIONES EN RED CON OTROS TIEMPOS, ESPACIOS Y GENERACIONES ROGER SCRUTON, TRADICIONES Y EDUCACIÓN

la Educación: localización de fuentes relevantes; lectura, análisis crítico y comparativo de los textos; interpretación hermenéutica y elaboración de conclusiones y propuestas. Este estudio pone de manifiesto que obrar de acuerdo con la tradición denota un tipo de acción intencional que contiene en sí misma el principio de su evolución. Por otra parte, se subraya que no existen tradiciones individuales, sino que siempre son compartidas por un grupo humano, constituyendo el fondo común de expectativas de una sociedad. Las tradiciones son plurales y cada cultura se caracteriza por una corriente central que ha superado la prueba del paso del tiempo y sirve como modelo y fuente de inspiración en el presente. Desempeñan una labor esencial en la tarea educativa, particularmente en lo que respecta a su función socializadora. En definitiva, asumir lo valioso de una tradición no se opone al progreso, sino que lo potencia, al establecer redes intencionales entre los miembros pasados, presentes y futuros de la sociedad.

Palabras clave: educación; tradición; transmisión educativa; cultura; R. Scruton; A. MacIntyre.

\section{ABSTRACT}

In our days it is frequent to despise the value of cultural, scientific and philosophical traditions because these link us to a time that has passed. Those who claim their value and the essential role they play in human life and education are disqualified as conservatives, falsely accused of trying to anchor subjects to a past that is no longer valid, as if they were enemies of progress, development and innovation. This article analyzes a different way of understanding tradition as is presented by renowned contemporary authors like R. Scruton, A. MacIntyre and R. S. Peters. For them, assuming traditions allows us to establish fruitful intentional networks with those who preceded us, with our contemporaries and with the unborn. According to the theoretical nature of this work, philosophical methodology is used: location of relevant sources; reading, critical and comparative analysis of texts; hermeneutic interpretation and elaboration of conclusions and proposals. This study denotes that following a tradition is an intentional behavior that contains in itself the principle of its own evolution. There are no individual traditions: they are shared by a human group and conform the common background of expectations of society. Furthermore, traditions are plural and each culture is characterized by a central current that has passed the test of time and serves as a model and as a source of inspiration for those who live in the present. Traditions play an essential role in education, especially regarding its socializing function. Assuming the value of a traditions is not opposed to progress, but rather empowers it, by establishing intentional networks between past, present and future members of society.

Key words: education; tradition; educational transmission; culture; R. Scruton; A. MacIntyre. 


\section{INTRODUCCIÓN}

Vivimos en sociedades sometidas a acelerados procesos de innovación que fijan la mirada hacia el futuro; y estamos conectados por redes que nos vinculan con casi todo lo que está ocurriendo en el presente. En este clima social, defender el valor de las tradiciones —familiares, culturales, científicas, educativas, de pensamiento, etc.suele estar mal visto, porque estas hacen referencia a un tiempo pasado que, se dice, ya ha perdido vigencia. Y quienes aprecian positivamente el valor y la función que éstas desempeñan en la vida humana y en la tarea educativa son tildados de conservadores, o incluso de retrógrados, como si pretendieran anclar a los sujetos a un pasado que ya caducó o fueran enemigos del progreso y la innovación. Esta crítica - que tiene mucho de prejuicio y de ignorancia- desconoce el auténtico sentido de la tradición tal como se ha entendido en la filosofía y la literatura (Eliot, 1920) y como proponen destacados pensadores contemporáneos como George Steiner, Alasdair MacIntyre, François-X. Bellamy, Roger Scruton o Richard Pring, entre otros. Y esto plantea un serio problema social porque, como señala acertadamente Marín (2018), cuando faltan las tradiciones se multiplican las adicciones.

En nuestros días, el desconocimiento generalizado de la historia convierte a muchos jóvenes en elementos desarraigados de una sociedad líquida, que carecen de los apoyos necesarios sobre los que forjar con sentido un relato de la propia vida o proyectar significativamente el futuro. La sensación de falta de raíces se agrava por el mal uso que se hace de las TIC: éstas brindan gratificaciones sensibles inmediatas sin tener que hacer apenas esfuerzo, proporcionan información en directo sobre casi todo, y reclaman respuestas instantáneas a los estímulos recibidos sin tiempo para la comprobación crítica y la reflexión. Así, muchos jóvenes viven en una especie de «utopía digital», en expresión de Bellamy (2018): piensan que ya no es necesario aprender nada, porque todos los conocimientos han quedado almacenados para siempre en la red y son accesibles en todo momento desde cualquier lugar.

Por contraste, algunos intelectuales contemporáneos subrayan la necesidad de recuperar el valor de la memoria para constituir identidades personales y colectivas congruentes, y para comprender mejor la temporalidad humana (Alvira, 2018). Y señalan la importancia de transmitir ese tesoro de sabiduría - teórica, práctica, técnica y moral - acumulado por la humanidad a lo largo de los siglos que se contiene en las tradiciones, tanto académicas como populares. El análisis de sus trabajos plantea dos cuestiones de gran calado educativo:

a) ¿Es posible prescindir del legado de bienes materiales, científicos y culturales de que dispone nuestra generación, que son fruto del trabajo esforzado de quienes nos precedieron?

b) ¿Sería justo privar a quienes nos sucederán en el futuro de esa herencia que nosotros hemos recibido? 
En definitiva, lo que se cuestiona es si nuestra generación obra bien ignorando en el presente el patrimonio cultural recibido, y si está legitimada para privar de ese legado a las generaciones futuras.

En este sentido, Sacks (1997, p. x) hace notar cómo toda la riqueza cultural de una sociedad cuelga, como suspendida, del frágil hilo de seda que es la memoria. Si una generación dejara de comunicar a los hijos lo aprendido de sus antepasados, el gran tesoro de conocimientos heredados se perdería. Basta con que la transmisión de la cultura falle en una sola generación para que colapse todo el edificio del saber acumulado, como se comprueba en el caso de la desaparición de antiguas culturas ágrafas. En la actualidad, por ejemplo, no somos capaces de interpretar el significado de los kipus de los Incas, porque hubo un momento en que se quebró el débil hilo de la memoria que sustentaba el saber, haciendo imposible su futura recuperación.

En los próximos apartados describiremos qué son las tradiciones, el papel que desempeñan en la constitución de la propia identidad y en el proceso educativo, y la responsabilidad que nos incumbe en el presente respecto a su transmisión a las generaciones futuras, de acuerdo con las propuestas del filósofo británico Sir Roger Scruton, fallecido hace unos meses. Prestar atención a estos temas se muestra especialmente importante en nuestros días, pues no solo estamos llamados a dejar tras nuestro paso un planeta sostenible desde el punto de vista ecológico, sino que somos también responsables de la sostenibilidad cultural de la vida humana en el futuro.

\section{LA CONDICIÓN HUMANA: PRESUPUESTOS ANTROPOLÓGICOS}

Desde las primeras reflexiones filosóficas en la Grecia clásica, las preguntas fundamentales sobre la condición humana - ¿Quién soy yo? ¿De dónde vengo? ¿Dónde me dirijo? ¿Qué me cabe esperar? —no ha dejado de formularse entre quienes se han tomado en serio su vida. En la segunda mitad del siglo XX, con el desarrollo de la filosofía existencialista y la deconstrucción, la pregunta antropológica ha experimentado un giro copernicano. Ya no interesa tanto saber "quién soy yo» sino "quién digo yo que quiero ser». En cierto sentido, esta segunda forma de preguntar también es legítima y ya Píndaro recomendaba: llega a ser el que eres. Pero tal como se formula en nuestros días, tiene un tinte de autosuficiencia preocupante: recuerda demasiado a la quimera del self-made man que "puede llegar a ser cualquier cosa" porque «si quiere, puede»; afirmación que alcanza su máxima cota —entre delirante y patética- de la mano de la utopía transhumanista.

Parece oportuno, por tanto, recordar algunas cuestiones fundamentales acerca de la condición humana y su contexto, si se desea comprender con más profundidad quiénes somos, quiénes estamos llamados a ser, y qué papel desempeñan las tradiciones y la educación en este proceso. 


\subsection{Seres corpóreos y temporales}

La pertenencia del ser humano al reino animal es una de las pocas afirmaciones en las que se constata un consenso universal. Desde posturas animalistas se puede cuestionar si somos, o no, un "animal especial»; pero nadie pone en duda que lo seamos y que pertenecemos al orden de los mamíferos. En cuanto animales, tenemos un cuerpo que - por ser material - está sometido a las leyes físicas y - como cualquier otro organismo vivo — obedece a las leyes de la biología; aunque es verdad que gracias a la razón podemos comprender, utilizar para nuestro beneficio y trascender intencionalmente ambos tipos de leyes.

La condición corpórea constitutiva de nuestra existencia nos coloca inexorablemente en unas coordenadas de espacio y tiempo que Kant — con aguda intuición- elevó a la categoría de formas a priori de la sensibilidad. Estamos situados, existimos espacialmente en nuestro cuerpo y en nuestro entorno; y no podemos eludir, detener o revertir el transcurso del tiempo, ese enigma que ha interesado a grandes filósofos desde San Agustín a Bergson y que sigue siendo un misterio para cada ser humano que se para a pensar sobre el transcurrir de su propia vida.

Que el ser humano exista en términos corpóreos e históricos significa que no podemos superar completamente los límites de nuestra situación y que las coordenadas espacio-temporales son el presupuesto necesario para la comprensión de uno mismo y del mundo. El sentido de la propia existencia se juega en este espacio y en este tiempo; afrontando la tarea de constituirnos y construir el mundo que nos rodea, hasta el punto de que se ha llegado a afirmar que «la identidad de lo humano no es otra cosa que poseer el tiempo, hacerse valedor de su temporalidad». (Rodríguez Valls, 2017, p. 159). Dado que la conciencia humana está situada, pretender ignorar el contexto particular y la historia que nos ha forjado, sería un intento tan vano como querer salir de la propia piel. Somos, estamos, vivimos, insertados en un lugar, un tiempo y una tradición cultural que son concretos, particulares que nos configuran y nos ofrecen las coordenadas de significación necesarias para acceder al conocimiento de la realidad exterior y para comprendernos a nosotros mismos.

La temporalidad propia de la condición humana constituye una dimensión ineludible de la existencia y se despliega en dos vertientes. Por una parte, el fenómeno de la globalización y el desarrollo de las TIC nos permiten establecer relaciones sincrónicas con un gran número de nuestros contemporáneos, compartiendo con ellos el presente a nivel planetario; y experimentamos también la dimensión diacrónica de nuestra temporalidad al evocar recuerdos — de los que extraemos enseñanzas y experiencia, placer y dolor-, y proyectar el futuro que nos gustaría protagonizar a nivel personal y también como sociedad. Porque percibimos que la temporalidad humana no se estructura como mera duración individual, sino que la biografía de cada persona forma parte de otras muchas historias que, cuando se contemplan desde la perspectiva de una comunidad, se comprenden como tradiciones (MacIntyre 1992) que se presentan como realidades plurales e históricamente cambiantes. 


\subsection{Animales culturales}

Los humanos somos seres que crean cultura, y ésta es una categoría antropológica exclusiva y fundamental. La falta de especialización biológica del organismo humano y su carácter racional hacen posible y reclaman, al mismo tiempo, la creación cultural. (G. Amilburu et al., 2019). Así, para llegar a ser plenamente humano es necesario poseer la estructura biológica propia de la especie y haber interiorizado una forma cultural particular. Siguiendo una tradición filosófica firmemente arraigada en la Antropología contemporánea (Cassirer, 1973; Geertz, 1983; etc.), se puede sostener que el ser humano es, por naturaleza, un animal cultural (G. Amilburu, 2010); y la cultura nos va haciendo cada vez más humanos, mejorando las condiciones materiales de nuestra vida y contribuyendo también —aunque no de manera automática- al crecimiento moral.

Gracias a la creación cultural, la humanidad ha ido atesorando en el transcurso de las generaciones un cúmulo de conocimientos y un potencial operativo cada vez mayores. Así, quienes llegan ahora a este mundo tienen a su disposición no solo las capacidades biológicas y racionales innatas de la especie sino también el legado cultural forjado a lo largo de los siglos: conocimientos, instituciones, ordenamientos jurídicos, instrumentos, técnicas, obras de arte, etc. En ese sentido, como ya señaló Aristóteles, la cultura constituye una especie de segunda naturaleza (Choza, 1985, p. 201) que potencia exponencialmente la capacidad operativa biológica del ser humano.

Pero este acervo cultural no se puede recibir pasivamente, como sucede con el patrimonio genético, sino que alguien ha de presentarlo ante nosotros y enseñarnos cómo hacerlo propio. La cultura se interioriza gracias a la educación, cuando se incorpora a las propias capacidades naturales en forma de hábitos intelectuales, volitivos, motores, técnicos, etc. (Ibíd.). En esa línea se puede afirmar que el camino que nos permite constituir la propia identidad y llegar a ser nosotros mismos, pasa necesariamente por la asimilación de la herencia cultural que se nos transmite junto con nuestra propia humanidad a través de los procesos de enseñanza-aprendizaje de carácter formal, no formal e informal.

\subsection{Seres dependientes y vulnerables}

El tercer supuesto antropológico a considerar en este contexto es la dependencia y la correlativa vulnerabilidad intrínsecas de nuestra especie (MacIntyre, 2001). Desde el punto de vista meramente pragmático, se comprueba que el ser humano es inviable sin la participación y la ayuda de sus semejantes: la propia existencia — nadie se ha dado la vida a sí mismo-, la supervivencia en la etapa infantil, la adquisición del lenguaje, etc., muestran por la vía de los hechos que no somos autónomos ni autosuficientes, sino seres profundamente dependientes de otros. Asociarse, buscar apoyo, ayuda, protección, compañía y consuelo entre los 
semejantes, son actitudes espontáneas del ser humano que, en expresión de Aristóteles, es por naturaleza un animal social. La independencia y autonomía personal que caracteriza a los individuos adultos de nuestra especie, solo se forja a partir de múltiples dependencias anteriores. Por eso, aunque en los ambientes educativos contemporáneos se insiste mucho - y con razón - en la formación de personas autónomas, con pensamiento propio, que puedan realizar elecciones por sí mismos, no estaría de más subrayar igualmente la necesidad de reconocer todo lo que nos ha sido dado y que ha hecho posible que maduremos hasta la edad adulta (Ibíd., p. 8) y, en consecuencia, fomentar actitudes de agradecimiento por lo recibido.

\section{ROGER SCRUTON Y LA TRADICIÓN}

Una vez bosquejado el contexto antropológico de nuestro discurso — la condición temporal, cultural, dependiente y vulnerable del ser humano- es posible apreciar mejor la importancia que tienen las tradiciones y su transmisión en el desarrollo de cada persona considerada individualmente, y de la sociedad en su conjunto.

Se entiende aquí por "tradición" una forma heredada de ver el mundo que comparte un grupo de personas y que responde a experiencias previas de diversa índole - familiares, culturales, científicas, religiosas, políticas, etc.- - Las tradiciones constituyen el trasfondo de conocimientos y modos de obrar compartidos que hacen posible que una sociedad funcione de un modo determinado, y que sus miembros comprendan su propia existencia y las relaciones que mantienen con sus semejantes y con el entorno. Las tradiciones surgen espontáneamente en cualquier agrupación humana, en todos los ámbitos donde nos relacionamos entre nosotros, tejiendo una red de conocimiento tácito acumulado que configura el marco de referencia compartido donde se comprende y se desarrolla el discurso social (Pring, 2018, pp. 63-64).

La característica más evidente de la tradición es que la validez de los conocimientos y de los modos de proceder que le son propios se justifican en relación con el pasado; porque el presente se comprende como cierta continuación de lo que ya sucedió y no como el comienzo absoluto de la identidad social, cultural o política de un grupo humano.

Uno de los pensadores que ha asumido con más empeño y acierto el estudio y defensa del concepto de tradición en las últimas décadas ha sido el filósofo británico Roger Scruton, recientemente fallecido. Vamos a desarrollar nuestra exposición al hilo de su pensamiento, también como un sencillo homenaje a sus aportaciones a la filosofía contemporánea.

Siguiendo el camino abierto por E. Burke y T.S. Eliot, Scruton rechaza el supuesto ilustrado según el cual cada individuo debería protagonizar su existencia como si fuera el primer ser humano que habita en el planeta, sin considerar ni beneficiarse de lo que pensaron e hicieron quienes vivieron antes que él. Scruton define la tradición como todo modo de obrar, costumbre, ceremonia, ritual y forma de participación en la vida institucional, que no se realiza mecánicamente sino por 
alguna razón que se sustenta en algo que ya sucedió. No es necesario que cada agente particular se sienta obligado a justificar racionalmente el motivo último por el que se hicieron así las cosas en el pasado, porque quien actúa de acuerdo con una tradición no la crea ni la diseña, sino que la asume y la sigue (Scruton, 1991, p. 278). La fuerza normativa de la tradición no es resultado del consentimiento social, ni deriva de la obligatoriedad de un contrato, sino que se experimenta como una amable carga de piedad y gratitud que reposa sobre nuestros hombros. El respeto a lo pretérito no se siente como debilidad sino como fortaleza, porque se valoran los logros alcanzados por generaciones anteriores, que han superado además la prueba de fuego del paso del tiempo. Si no se asume esta carga, la autonomía personal se vacía de contenido y acaba destruyéndose la sociedad, porque el orden social es condición de posibilidad del ejercicio de la libertad y el suelo del que se nutren los deberes y los valores que la acompañan (Ibíd., p. 9).

Cuando se desea comprender en profundidad el pensamiento de un autor, se recomienda prestar atención a dos perspectivas complementarias: por un lado, el lugar desde el que escribe - algún hecho relevante de su biografía, la formación recibida, etc., en definitiva, sus puntos de apoyo y de partida-; y por otro, saber contra quiénes argumenta, pues sobre ese trasfondo se concibe mejor su planteamiento. Por lo que respecta a Scruton, él parte de la convicción de que el ser humano es un ser social por naturaleza: reconoce la existencia de una serie de vínculos - que llama trascendentales - que le unen con sus semejantes, con quienes establece de modo espontáneo lazos de cooperación y compromisos, con vistas a la propia supervivencia y su pleno desarrollo. En ese sentido, el pensamiento de Scruton se opone al de quienes sostienen teorías contractualistas para explicar el origen de la sociedad civil. Él considera que la sociedad es —en sentido metafísico- anterior a los individuos que la componen, pues el «individuo» — como señalaron Burke y Hegel - es un "artefacto social»: fruto de ciertas condiciones históricas que lo ligan a costumbres, valores y expectativas sin las que se vería seriamente dañado o incluso incompleto en cuanto humano. Por lo tanto, considera que las tradiciones son realidades dignas de respeto, y cuando se rechazan se amputa voluntariamente al ser humano del orden social que hace posible la inculturación (Scruton, 2007a, p. 101).

Por otra parte, y para entender contra quiénes se sitúa, hay que considerar un hecho al que el propio Scruton atribuye una importancia decisiva a la hora de configurar su postura filosófica e identificar a sus adversarios intelectuales desde ese momento (Scruton, 2005). Se trata de las protestas estudiantiles promovidas por algunos intelectuales en Francia a principios de los años 70 del siglo XX, de las que fue testigo de excepción, porque se había trasladado a vivir allí para intentar abrirse camino como escritor freelance al finalizar sus estudios en Cambridge. Quedó consternado al observar cómo una generación de hijos de papá a los que todo — situación económica, estilo de vida, formación universitaria, etc. - se les había regalado sin que tuvieran que hacer ningún esfuerzo, asumían ciegamente 
los presupuestos revolucionarios de la izquierda marxista sin someterlos a reflexión crítica, y se dedicaba a destruir — también materialmente- el legado cultural recibido, sin formular ninguna propuesta para después de su demolición. Los sumos sacerdotes de la postmodernidad y los comisarios políticos del liberalismo - como Scruton les llamó- acometieron con furia iconoclasta la tarea de «deconstrucción de la cultura occidental», con el único propósito de desestabilizar las costumbres e instituciones en las que habían crecido, y liberarse de lazos perdurables y vinculaciones estables. No es posible detenernos a examinar en profundidad la crítica de Scruton a los planteamientos de la filosofía deconstrucción y las razones últimas de su toma de postura personal; solo indicaremos que él lo hizo detenidamente en su obra Thinkers of the new left (1986), que revisó y reeditó posteriormente con el título Fools, frauds and firebrands: thinkers of the new left (2015), traducida al castellano por Rialp en 2017. Así, únicamente señalaremos ahora que, como reacción ante el desmantelamiento intelectual generado por esos autores, Scruton se descubrió a sí mismo como "conservador", no en cuanto a la pertenencia a un partido político, sino en el ámbito vital, afectivo e intelectual. Y asumió personalmente la defensa del modo de conocer y de juzgar que admite que existen realidades - objetos, modos de proceder, costumbres, instituciones, etc.- que son valiosas en sí mismas y beneficiosas para el ser humano y, por tanto, merecen ser "conservadas", preservadas, protegidas y, en su caso, compartidas con otras personas y transmitidas a generaciones futuras. En este sentido, Scruton se situó frente a los planteamientos «revolucionarios» y asumió el compromiso intelectual de recuperar y defender ideas y valores que habían sido tirados por la ventana de manera arrogante e irresponsable por quienes pretendían subvertir el orden social por considerarlo una fortaleza de estructuras de poder que aprisionaban al hombre moderno, a quien ellos se sentían llamados a emancipar (Dooley, 2010, p. xi).

Scruton considera que el pensamiento postmoderno - tal como él lo percibió encarnado en los protagonistas de la revolución de mayo del 68 en Franciaarranca al ser humano de su bumus intelectual, cultural, político y espiritual, al declarar la guerra a la tradición: a ese repertorio de conocimientos y modos de obrar elaborados y transmitidos socialmente durante generaciones. Y para sanar la situación de desconcierto y desamparo que surge cuando se arrancan las raíces y uno se ve obligado al vivir en el vacío, él se esfuerza por recuperar y redescubrir el sentido de las realidades cotidianas del ámbito de la vida ordinaria: la relación con la naturaleza, el amor a la propia tierra, la familia, el hogar, las costumbres, los valores compartidos, etc.

Scruton constata que el planteamiento deconstruccionista no aporta nada a la existencia humana; su originalidad consiste en haber dado carta de ciudadanía a un mundo de transgresión: un modo de vida que no puede prolongarse por mucho tiempo, pues lleva en sí mismo la semilla de su autodestrucción al negar los valores que permiten a cualquier grupo humano a perpetuarse y subsistir. Por contraste, 
Scruton elabora una filosofía de la afirmación que reivindica el valor antropológico de lo familiar y cercano - el paisaje, la comunidad- para contrarrestar la labor destructora del nihilismo y el odio. En definitiva, su filosofía pretende aportar argumentos capaces de devolver la paz y ofrecer consuelo a quienes estén cansados de tanta negación, destrucción y protesta (Ibíd., p. xii)

Para ello, trata de desenmascarar la profunda falsedad de los planteamientos de los pensadores de la nueva izquierda en su empeño por desprestigiar y echar por tierra las instituciones y los valores de la sociedad en nombre de una libertad puramente utópica; porque la única libertad real que existe y es digna de ser defendida es la libertad concreta, encarnada, situada que cada persona es (Scruton, 2015). Y pone de manifiesto cómo han sido precisamente los valores y las instituciones que se han ido forjando en el seno de la tradición occidental —a pesar de sus innegables carencias, defectos y equivocaciones - los que han asumido la defensa de esa libertad durante los siglos (Dooley, 2009, p. 6).

Y señala que los errores antropológicos sobre los que se apoyan las filosofías de la sospecha y el resentimiento se hacen patentes con solo abrir los ojos y contemplar las heridas infringidas a las vidas de tantas personas y al tejido social tras varias décadas de transgresión. Entre ellas, el nihilismo activo que afecta a muchas formas de convivencia y a las estructuras políticas, dejando un poso de fragmentación, desconfianza, individualismo, desorden social, miedo y amenazas que están presentes en tantos ambientes (Scruton, 1991, p. 29; 2006, p. 194; etc.). A la vista de esos hechos Scruton se reafirma en su propósito de defender la función de las tradiciones, el papel que éstas desempeñan en la vida humana, y la importancia de transmitirlas a las nuevas generaciones mediante la educación. Esta postura hizo de Scruton un blanco fácil para las campañas de acoso y derribo orquestadas por la dictadura de lo políticamente correcto - la última, pocos meses antes de su fallecimiento, cuando fue cesado - y rehabilitado públicamente en el cargo- como presidente de la Building Better Building Beautiful Commission del Gobierno británico.

\section{CARACTERísticas de LA TRAdición}

Un saber, un modo de actuar y proceder pasa a formar parte de la tradición cuando da buen resultado y permanece a lo largo del tiempo. Constituye, por tanto, el recordatorio de un logro, de una conquista, y no el último intento en una serie de inicios fallidos. Por eso las tradiciones pueden reclamar cierta lealtad por parte de quienes las asumen: porque éstas apuntan hacia algo perdurable que sobrevive y llena de significado los actos que emergen de ellas (Scruton, 2006, p. 281).

Scruton (2007a, p. 555) enumera sintéticamente las principales características de la tradición: 
a. Actuar de acuerdo con una tradición supone un modo de obrar intencional distinto de las rutinas, hábitos, mecanismos de defensa y reacciones que pueden atribuirse a causas estrictamente fisiológicas.

b. Una tradición contiene en sí misma el principio de su propio desarrollo, porque las acciones intencionales siguen siempre al conocimiento, y este aumenta y evoluciona a lo largo del tiempo.

c. Los motivos que justifican asumir una tradición y actuar de acuerdo con ella son inmanentes al propio agente; es decir, responden a percepciones que tiene el sujeto en relación con la validez de ciertas prácticas en el momento de llevarlas a cabo.

d. No existen tradiciones individuales. Una tradición es siempre compartida y se comprende como tal porque hace referencia a prácticas sociales, y acomodándose a ellas, el agente goza de la aprobación de la comunidad. Así, la tradición no debe considerarse principalmente un conjunto de conocimientos teóricos acerca de los hechos, sino más bien como un tipo de saber que permite discernir qué conviene hacer para alcanzar el éxito al realizar una tarea; entendiendo aquí por éxito no solo la eficacia técnica de una acción, sino que el agente sea bien acogido en el grupo social: porque ésta es una de las más profundas aspiraciones del ser humano. Asumir una tradición, por tanto, permite intuir qué conviene hacer, decir u omitir cuando estamos con nuestros semejantes (Scruton, 2014, p. 21).

e. Las tradiciones tejen el telón de fondo de las expectativas comunes de un grupo humano, y permiten juzgar si una novedad constituye una desviación o una aportación creativa al legado común. De igual manera, gracias a que juzgamos la actuación de la gente proyectada sobre ese trasfondo común, podemos percibir su carácter propio, original, y sus rasgos individuales.

f. Por último, hay que destacar que las tradiciones son plurales, y pueden coexistir pacíficamente o convertirse en rivales. Cada grupo social, cada cultura, se caracteriza por una corriente central de tradiciones que no solo ha superado el paso del tiempo, sino que continúa siendo una fuente de inspiración para los miembros de esa sociedad (Scruton, 2007b, p. 4).

Toda tradición artística, cultural, de pensamiento, etc., configura un sistema de convenciones, de sobreentendidos, referencias y expectativas compartidas que están en constante desarrollo. La tradición presenta siempre dos caras: está en continua evolución y en permanente continuidad; y — como señalaba Elliot - se rehace con cada elemento que se le añade, adaptando el pasado al presente y acomodando el presente al pasado (Scruton, 2005). Los conocimientos y modos de obrar tradicionales son simultáneamente recibidos y recreados; y el mismo hecho de que hayan sido heredados, asimilados mediante el aprendizaje, hace posible su renovación y evolución.

Asumir una tradición para actuar de acuerdo con ella no anula la libertad humana, porque no obliga a la reproducción mecánica de un conjunto de reglas 
arbitrarias o de meras convenciones y acuerdos; sino que las tradiciones proporcionan repertorios de respuestas eficaces que han sido descubiertas o elaboradas por quienes nos precedieron para solucionar preguntas recurrentes y problemas fundamentales de la condición humana. Las propuestas de la tradición pueden ser muy sencillas o, por el contrario, estar encarnadas en prácticas sociales complejas, y no es necesario que cada persona que las asume elabore una justificación racional completa de los motivos que avalan su seguimiento, porque se percibe que la depositaria y garante de ese tesoro de sabiduría acumulada, es la sociedad en su conjunto. Y se intuye también que sería peligroso rechazarlo por el solo hecho de que forma parte de la tradición (Scruton, 2014, p. 21).

Actuar de acuerdo con la tradición no prefija de modo absoluto la concepción del mundo que cada persona se forja; la relación de cada individuo con la tradición a la que pertenece está entretejida de confianza y extrañeza. En el momento de la socialización primaria, la tradición se asume de manera acrítica; pero más adelante el ser humano se cuestiona su validez, de modo que las relaciones con la propia tradición se vuelven hermenéuticas, confrontando sus contenidos con las propias percepciones posteriores y los referentes de otras tradiciones de las que se tiene noticia.

La tradición no actúa como una fuerza externa que determina completamente la vida humana, ni como algo inerte y acabado: somos nosotros quienes comunicamos a la tradición la fuerza que ésta posee, mientras vivimos y formamos parte de su proceso de transmisión. Así, cuando la libertad humana se considera situada en el seno de la tradición, se reconoce beneficiada por los logros de quienes le precedieron y potenciada para obrar con originalidad (Scruton, 2006, p. 167). Y el sentimiento que ese hecho despierta de manera espontánea, no es otro sino el agradecimiento.

\section{EDUCACIÓN Y TRANSMISIÓN}

A mediados del siglo XX, y casi al mismo tiempo que se producían los disturbios de mayo del 68 en Francia, el filósofo británico R.S. Peters proponía un nuevo modo de entender la educación, como tarea civilizadora y socializadora. La presentaba con la metáfora del proceso de iniciación de las personas jóvenes en las tradiciones públicas del grupo humano al que pertenecen (Peters, 1966, pp. 46-62). Antes de ser educados, afirma, los niños estarían en la misma situación que los bárbaros, fuera de las puertas de la urbe. La educación les conduce hacia la ciudadela interior, les capacita para entender lo que allí sucede, y para tomar parte en la conversación de la humanidad que se desarrolla a lo largo de las generaciones, según la conocida expresión de Michael Oakeshott. En el proceso educativo una generación entrega a la siguiente un valioso legado: la propia tradición cultural. Y con ello se favorece el desarrollo de estados mentales y capacidades operativas deseables en quienes 
aprenden, de modo que puedan contribuir a su vez, con pleno derecho y conocimiento, al progreso de la sociedad a la que son incorporados (Ibíd.).

Más recientemente, el filósofo francés F.-X. Bellamy ha llamado la atención sobre lo que denomina el misterio de la mediación: el hecho de que todas las disposiciones naturales del ser humano necesitan una mediación educativa para actualizarse (Bellamy, 2018, p. 97). Pone en guardia frente a un error frecuente que consiste en considerar el capital cultural transmitido en la tradición como una especie de equipaje que se lleva a cuestas y que convendría aligerar si se desea avanzar más deprisa. De ese modo no se percibe que la cultura pertenece más al ámbito del «ser» que al del «tener» humano (Ibíd., p. 93). Considerar la cultura como si fuera una maleta que llevamos con nosotros significaría, entre otras cosas, admitir la existencia autónoma del propietario — tanto con equipaje como sin él- y esto no sucede así en la realidad: la cultura no es un añadido — algo que tenemos - sino que nos configura, y forma parte de lo que somos.

A la luz de lo que ya se ha dicho, no es difícil reconocer la importancia de la mediación cultural para el desarrollo de la vida humana, y comprender que la transmisión de la herencia cultural a los hijos o a los alumnos no restringe su autonomía sino que, por el contrario, les ofrece las herramientas que van a necesitar para crecer y desarrollarse como seres humanos únicos, irrepetibles (Ibíd., p. 144). Bellamy atribuye una importancia fundamental a la transmisión de la cultura en la educación. "La escuela — sostiene- no puede contribuir a esa misión educativa más que asumiendo, simplemente, la tarea que le es propia: transmitir una cultura». (Ibíd., p. 149). Y se lamenta de que en casi todos los sistemas educativos occidentales se está padeciendo una "crisis de la transmisión", que comenzó a extenderse con el pensamiento ilustrado y se ha consumado en la postmodernidad, invitando al sujeto a fiarse solo de las propias ideas claras y distintas, y a poner en tela de juicio el valor de las costumbres, el peso de la historia y cualquier principio de autoridad. Con ello, se cercenan las posibilidades de crecimiento humano hasta límites preocupantes, como es posible contemplar en amplios sectores de nuestra "Sociedad del conocimiento".

La situación es preocupante porque, como señalaba recientemente un autor africano, parece que el hombre occidental moderno es amnésico. Aspira a la ruptura con el pasado, mientras que idolatra lo novedoso. Cultiva una especie de hostilidad agresiva en contra de la tradición - y, de modo más general, en contra de cualquier herencia-, sin percibir que vivir en el cambio permanente priva a la existencia humana de una brújula para su vida. La relación conflictiva de la modernidad con la idea de la tradición obedece a una crisis antropológica profunda: el hombre moderno teme que sus raíces se conviertan en un yugo, y prefiere renegar de ellas. Así se cree más libre, pero en realidad se hace más vulnerable: es como una hoja muerta desprendida del árbol, a merced de cualquier viento ideológico (Sarah, 2019, pp. 247-249). 
La ruptura, la deconstrucción, la duda, la sospecha, el resentimiento y la transgresión se han convertido en los presuntos motores del progreso. Se rechaza cualquier herencia para hacer tabula rasa del pasado y poder repudiar la cultura que nos precede; se desprecian los modelos y los vínculos, crece el deseo sistemático de ruptura con la figura del padre, etc. Estos gestos posmodernos — añade- encierran a nuestras sociedades en los límites de la dictadura del presente y conducen a catástrofes humanas, políticas y económicas (Ibíd., p. 255) como desgraciadamente estamos presenciando.

\section{Conclusión}

Este artículo, apoyándonos en las aportaciones del filósofo Roger Scruton, se ha puesto de manifiesto que obrar de acuerdo con la tradición denota un tipo de acción intencional que contiene en sí misma el principio de su evolución. Por otra parte, se señala que no existen tradiciones individuales, sino que siempre son compartidas por un grupo humano, constituyendo el fondo común de expectativas de una sociedad. Las tradiciones son plurales y cada cultura se caracteriza por una corriente central que ha superado la prueba del paso del tiempo y sirve como modelo y fuente de inspiración en el presente. Éstas desempeñan una labor esencial en la tarea educativa, particularmente en lo que respecta a la tarea de socialización de los seres humanos. En definitiva, se ha mostrado que asumir lo valioso de una tradición no se opone al progreso y la innovación, sino que los potencia, al asumir la sabiduría teórica, práctica y moral acumulada durante generaciones, y al permitir establecer redes intencionales entre los miembros pasados, presentes y futuros de la sociedad.

Teniendo en cuenta este modo de entender la tradición y el contexto antropológico que hemos delineado, es razonable sostener que hoy en día es aún más necesario que nunca que esforzarse por conocer, apreciar, agradecer, custodiar, someter a crítica, hacer progresar y transmitir, los beneficios contenidos en la herencia recibida. O, al menos, despertar esta conciencia entre quienes nos dedicamos a la educación. Porque

enseñar, a fin de cuentas, no es otra cosa sino entregar a quienes nos suceden un tesoro que, a su vez, nos entregaron quienes nos preceden; y la ruptura de esa cadena es siempre un hurto, a veces también una herida irrestañable. (Prada, 2019, p. 8).

\section{REFERENCIAS BIBLIOGRÁFICAS}

Alvira, R. (2018). Elogio de la memoria. Nuestro Tiempo, (700), 84.

Bellamy, F. X. (2018). Los desheredados. Por qué es importante transmitir la cultura. Encuentro. Cassirer, E. (1973). Filosofía de las formas simbólicas. FCE.

Choza, J. (1985). Antropologías positivas y antropología filosófica. Cenlit. 

ROGER SCRUTON, TRADICIONES Y EDUCACIÓN

Dooley, M. (2009). Roger Scruton. The Philosopher on Dover Beach. Continuum.

Dooley, M. (2010). The Roger Scruton Reader. Bloomsbury.

Eliot, T. S. (1920). Tradition and the individual talent. En The sacred wood. Essays on poetry and criticism (pp. 42-53). Methuen. https://archive.org/stream/sacredwoodessays00eli orich?ref=ol\# ${ }^{\text {page }} /$ n19/mode/2up/search/tradition

G. Amilburu, M. (2010). Cultura. En F. Fernández Labastida y J. A. Mercado, J.A. (Eds.), Pbilosophica: Enciclopedia filosófica on line. http://www.philosophica.info/voces/cultura/ Cultura.html

G. Amilburu, M. et al. (2019). Antropología de la educación. La especie educable. Síntesis.

Geertz, C. (1983). La interpretación de las culturas. Gedisa.

MacIntyre, A. (1992). Tres versiones rivales de la ética. Enciclopedia, genealogía y tradición. Rialp.

MacIntyre, A. (2001). Animales racionales y dependientes. Paidós.

Marín, H. (2018). Los nuevos adeptos. La Opinión, 18-11-2018. https://www.laopiniondemurcia.es/opinion/2018/11/20/nuevos-adeptos/973537.html

Peters, R. S. (1966). Education as initiation. En Ethics and education (pp. 46-62). Allen \& Unwin.

Prada, J. M. de (2019). Una grave mutilación. En XL Semanal, 3 febrero, 8. https://www. xlsemanal.com/firmas/20190204/una-grave-mutilacion-juan-manuel-prada.html

Pring, R. (2018). The future of publicly funded faith schools. A critical perspective. Routledge.

Rodríguez Valls, F. (2017). Orígenes del hombre. La singularidad del ser humano. Biblioteca Nueva.

Sacks, J. (1997). The politics of hope. Jonathan Cape.

Sarah, R. (2019). Se hace tarde y anochece. Palabra.

Scruton, R. (1986). Thinkers of the new left. Longman.

Scruton, R. (1991). Conservative texts. Macmillan.

Scruton, R. (2005). Gentle regrets. Thoughts from a life. Bloomsbury.

Scruton, R. (2006). A political philosophy. Continuum.

Scruton, R. (2007a). A dictionary of political thought. Macmillan.

Scruton, R. (2007b). Culture counts. Faith and feeling in a world besieged. Encounter Books.

Scruton, R. (2014). How to be a conservative. Bloomsbury.

Scruton, R. (2015). Fools, frauds and firebrands: Thinkers of the new left. Bloomsbury. 